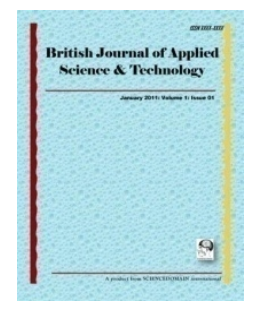

British Journal of Applied Science \& Technology

4(6): 853-878, 2014

SCIENCEDOMAIN international

www.sciencedomain.org

\title{
Characterization and Corrosion Resistance of Galvanized Steel/Passivation Composite/ Polyurethane Paint Systems
}

\author{
A. R. Di Sarli ${ }^{1 *}$, C. I. Elsner ${ }^{1,2}$ and C. R. Tomachuk ${ }^{3}$ \\ ${ }^{1}$ CIDEPINT: Research and Development Centre in Paint Technology (CICPBA-CONICET LA \\ PLATA); Av. 52 s/n entre 121 y 122. CP. B1900AYB, La Plata, Argentina. \\ ${ }^{2}$ Engineering School, National University of La Plata, Av. 1 Esq. 47. CP. B1900TAG, \\ La Plata, Argentina. \\ ${ }^{3}$ Energy and Nuclear Research Institute, IPEN/CNEN-SP, CCTM, Av. Prof. Lineu Prestes, \\ 2242, CEP 05508-000, São Paulo, SP, Brazil.
}

Authors' contributions

This work was carried out in collaboration between all authors. All authors have actively contributed to carry out each step of the present paper. All authors read and approved the

final manuscript.

Original Research Article

Received $11^{\text {th }}$ September 2013

Accepted $12^{\text {th }}$ November 2013

Published $12^{\text {th }}$ December 2013

\section{ABSTRACT}

The corrosion performance of electrogalvanised steel sheets pre-treated with a $\mathrm{Cr}^{3+}$ or $\mathrm{Cr}^{+6}$-based conversion layer and then covered with polyurethane-waterborne topcoat paint has been studied. The pre-treated metallic panels were coated with one of the three tested polyurethane (PU) topcoat paints, in which the dispersion type was the formulation variable. The pigment was $\mathrm{TiO}_{2}$ (rutile) with a PVC value of 10 . Before and after the immersion in $0.05 \mathrm{M} \mathrm{NaCl}\left(\mathrm{pH} 5.70\right.$ ) or $0.1 \mathrm{M} \mathrm{Na}_{2} \mathrm{SO}_{4}$ ( $\mathrm{pH} 6.36$ ) solutions, replicates of the different samples were subjected to standardized tests (porosity, gloss and color, hardness, flexibility). During the immersion, blistering and rusting degrees were evaluated through periodical visual inspections, while the coated steel performance was monitored by Electrochemical Impedance Spectroscopy (EIS) measurements. Initial (dry) and final (wet) paint adhesion was also determined. EIS data were interpreted and discussed in terms of the time dependence of the electrical (paint coating) and electrochemical (steel substrate) parameters associated with interfacial processes describing the metal/paint system deterioration. According to the electrochemical properties, visual inspection and

*Corresponding author: E-mail: ardisarli@gmail.com, ardisarli@cidepint.gov.ar; 
standardized tests results, it was concluded that the studied polyurethane-based polymeric films applied on pretreated electrogalvanised steel provided a very effective protection against corrosion as a result of their excellent barrier properties.

Keywords: Passivating; trivalent chromium; electrogalvanised steel; organic coating; impedance spectroscopy; corrosion.

\section{INTRODUCTION}

Electrogalvanised steel is being used increasingly for the manufacture of automobiles, domestic appliances, structures and other products. Many technologies have been developed to improve the quality and cost of zinc-coated sheets while trying to fulfill the stringent and diversify quality requirements from users. Among them to reduce the susceptibility of metallic coated steel to corrosion, the practice for many years has been to treat it with chromate conversion coatings. These are formed on metal surfaces because of the chemical attack that occurs when a metal is immersed in or sprayed with an aqueous solution of chromic acid or chromium salts to produce a thin film coating. The chemical attack facilitates the dissolution of some surface metal and the formation of a protective film containing complex chromium compounds [1]. The amorphous hydrated oxide mixture that is formed on the surface must involve oxidation of the substrate, followed by the precipitation of the dissolved metal occurring from an increase in $\mathrm{pH}$ at the surface due to reaction with the excess hydroxyl ions produced as a result of the cathodic (reduction) half reaction. Either reduction of dissolved oxygen or of water itself will cause an increase of the $\mathrm{pH}$ at the surface. Moreover that mixture promotes strong adhesion of the conversion coating to the substrate [2]. When the latter is zinc, the conversion layer protects against corrosion through barrier and passivation effects. The complex chromium oxide acts as a barrier while the $\mathrm{Cr}^{+6}$ contained in the film serves to re-passivated exposed metal. Water that comes in contact with the film dissolves the $\mathrm{Cr}^{+6}$ forming a chromate solution, which then forms a fresh passivation film on the surface. This is the reason for the "self-healing" ability of the chromate passivation film. However, due to health, safety and environmental concerns, the use of $\mathrm{Cr}^{+6}$ is being discontinued [3]. Based on the European Union RoHS Directive 2002/95/EC [4] and then followed by other countries, this proposal trends to eliminate $\mathrm{Cr}^{+6}$ and other substances from essentially all new electrical and electronic equipment by July 1 , 2006. As can be seen, this regulation did not prohibit the use of chromium, rather it prohibits the use of chromium in the hexavalent state, i.e., the chrome can be used in other valence states as for example $\mathrm{Cr}^{+3}$ [5]. The employment of $\mathrm{Cr}^{+3}$-based products allow the retention of some of the advantages of chromium based systems but as obtaining all the benefits of chromate is difficult to achieve with $\mathrm{Cr}^{+3}$, the latter must be applied at heavier coating weights to obtain the same corrosion protection as the former.

In line with the purpose of improving the zinc corrosion resistance, it should be noted that when this metal is protected by a painting system, its dissolution rate is related to the transport of corrosion inducing species (oxygen, ions) through the paint layer, the charge transfer and/or delamination processes at the metal/coating interface as well as to the composition-structural changes of the paint layer [6]. Moreover, the coated metal performance depends on the metal surface preparation, polymeric material, interfacial adhesion, environmental aggressiveness as well as of the coating cross linking degree, continuity, thickness and composition [7]. 
The application of organic coatings on conversion layers is required for producing structures where the zinc layer long lasting is addressed. This process implies to apply one or more coats of paint on the metallic surface and then a drying/curing period under, if possible, environmentally controlled conditions [8-13]. The production and applying processes of these polymeric materials usually causes Volatile Organic Compounds (VOCs) emissions, which involve serious environmental and public health problems. European standards impose limits to the use and emission of VOCs in industrial zones where painting cycles are working, reason by which the development of waterborne paints started to be considered [14-28]. In addition to hardness and abrasion resistance, they could provide thin thickness by coat and hence the film homogeneity and continuity become critical parameters Nevertheless, this kind of problem could be easily overcome by applying more coats. These products differ from the traditional paints in that the organic solvent content is less than $10 \%$ $(\mathrm{w} / \mathrm{w})$ but they offer excellent stability, small size particles can be pigmented using appropriated products and are compatible with a large variety of additives and curing agents. Several groups have reported the influence of particle morphology, surface treatment of inorganic pigments, corrosion inhibiting additives, fillers, dispersing agents and nature of the binder material on the performance of waterborne coatings [12,29-49].

Concerning the cure process of waterborne paints, during the drying cycle, the water present in the dispersion evaporates provoking the polymer solid particles deformation and coalescence due to surface tension forces. At the end of the evaporation period, a polymeric matrix with many dispersed particles is observed. Then, the inter-particles diffusion process of polymeric reticulation chains begin to give the final film, in which the particles appear forming groups $[28,50]$.

In this context, polyurethane coatings are used for a range of applications such as steel and concrete on bridges, tanks, pipes and other structures essential to the nation's infrastructure. Furthermore, on steel and concrete in chemical, pulp and paper, power and other industries due to their good hardness combined with excellent adhesion to metallic substrates, anticorrosive properties and weather resistance [51-54]. By all of these reasons, such paints have been studied by several authors, who determined variations of coating porosity resistance, coatings dielectric capacitance, polarization resistance, double layer capacitance [55-57] and also the relationship between electrolyte diffusion through the paint coat and the corrosion resistance of the underlying metal $[12,58]$.

The main purpose of the present work was to find coatings that besides of being an environmentally friendly alternative to $\mathrm{Cr}^{6+}$-based conversion treatments also provide a surface compatible with paints containing lower amount of VOCs. Therefore, as first step, the surface morphology, structure and chemical composition of the "as-received" electrogalvanised steel sheets subjected to $\mathrm{Cr}^{3+}$-based pre-treatments was characterized by Scanning Electron Microscopy (SEM) and Energy Dispersive X-Ray Spectroscopy (EDXS). Similar procedure was carried out on replicates of the electrogalvanised steel sheets pretreated with $\mathrm{Cr}^{6+}$, which were used as reference samples. Then, both types of pre-treated samples were covered with one of the three environmentally friendly polyurethane topcoats tested. Before and after immersion for 94 days in open to the air $0.05 \mathrm{M} \mathrm{NaCl}$ or $0.1 \mathrm{M}$ $\mathrm{Na}_{2} \mathrm{SO}_{4}$ solutions, properties of the paint film such as adhesion, flexibility, color, gloss, porosity, hardness, etc. were evaluated by using standardized (ASTM, ISO) tests. The anticorrosive performance of the whole protective system as a function of the exposure time in these solutions was also assessed through EIS measurements. 


\section{MATERIALS AND EXPERIMENTAL DETAILS}

\subsection{Preparation of Electrogalvanised and Passivated Samples}

The metallic substrates used in this work were identified and prepared as follow:

\section{$\underline{\text { 2.1.1 ZTRI samples }}$}

AISI 1010 steel sheets $(6.5 \times 10 \times 0.4 \mathrm{~cm})$ were industrially electrogalvanised from a cyanide-free alkaline bath containing $\mathrm{Zn}^{2+} 12.5 \mathrm{~g} \cdot \mathrm{L}^{-1}, \mathrm{KOH} 170 \mathrm{~g} \cdot \mathrm{L}^{-1}, \mathrm{~K}_{2} \mathrm{CO}_{3} 50 \mathrm{~g} \cdot \mathrm{L}^{-1}$, additive $10 \mathrm{~mL} . \mathrm{L}^{-1}$, brightening agents $1 \mathrm{~mL} \cdot \mathrm{L}^{-1}$, conditioner $10 \mathrm{~mL} \cdot \mathrm{L}^{-1}$, maintained at room temperature $\left(23 \pm 3^{\circ} \mathrm{C}\right)$ and using $2 \mathrm{~A}^{-\mathrm{dm}^{-2}}$ of cathodic current density. At the end of this step, the samples were covered with iridescent green-colored conversion treatment basically composed by $10 \mathrm{~g} . \mathrm{L}^{-1} \mathrm{Cr}\left(\mathrm{NO}_{3}\right)_{3} .9 \mathrm{H}_{2} \mathrm{O}, 2.5 \mathrm{~g} \cdot \mathrm{L}^{-1} \mathrm{Co}\left(\mathrm{NO}_{3}\right)_{3}$, organic acids (malonic and oxalic) and $\mathrm{HNO}_{3}$ for $\mathrm{pH}$ adjustment. The operating conditions in the industrial bath were: $\mathrm{pH}$ 1.8, temperature $60^{\circ} \mathrm{C}$, immersion time $60 \mathrm{~s}$ and pieces mechanically stirred;

\subsubsection{ZHEX samples}

Used as reference, AISI 1010 steel sheets $(6.5 \times 10 \times 0.4 \mathrm{~cm})$ were electrogalvanised using the same method above described but later they were covered with a yellow-colored conversion treatment composed by $4.6 \mathrm{~g} \cdot \mathrm{L}^{-1} \mathrm{Na}_{2} \mathrm{Cr}_{2} \mathrm{O}_{7} \cdot 2 \mathrm{H}_{2} \mathrm{O}$, conductive salts $(\mathrm{NaCl})$ and diluted $\mathrm{HCl}$ for $\mathrm{pH}$ adjustment. The operating conditions in the industrial bath were: $\mathrm{pH} 1.8$, temperature $23 \pm 3^{\circ} \mathrm{C}$, immersion time $30 \mathrm{~s}$ and pieces mechanically stirred.

In order to improve the steel surface cleaning and wet ability, before applying the zinc coating all the sheets were immersed in alkaline solution for 3 min and at $4 \mathrm{~A}_{\mathrm{dm}}{ }^{-2}$. Then, they were rinsed in deionized water, activated in $5 \% \mathrm{HCl}$ solution for $2 \mathrm{~s}$ and rinsed again in deionized water. Just after ending this step, the zinc surface was activated in $\mathrm{HNO}_{3}$ solution at $\mathrm{pH} 1 \mathrm{for} 10 \mathrm{~s}$, rinsed in deionized water and coated with the conversion layer. Finally, the samples were rinsed in deionized water and dried in an oven for $15 \mathrm{~min}$ at $80^{\circ} \mathrm{C}$. All of them were kept in desiccators at ambient temperature up to starting the tests.

\subsection{Paints Application on Passivated Electrogalvanised Steel Samples}

ZHEX and ZTRI samples were coated using environmentally friendly topcoat barrier polyurethane (PU) paints designed, formulated and prepared in the CIDEPINT laboratory. Tables $1 \mathrm{a}-1 \mathrm{c}$, which describe the most important characteristics of these paints, illustrate that both the commercial polyurethane dispersion was the main paint formulation variable and the pigment volume concentration (PVC) $=10$ was obtained using only the pigment $\mathrm{TiO}_{2}$ (rutile), with a particle size distribution from 0.1 to $10 \mu \mathrm{m}$ checked by the ASTM D1210-05 standard [59].

\subsection{Thickness Measurements}

The thickness of the passivated electrogalvanised layer was measured with the X-Ray Fluorescence Method, Helmut Fischer mod. XDL-B, while the corresponding to the dry paint films with the Elcometer mod. 300 coating thickness gauge, which uses a bare sanded plate as reference according to the ISO 2808-2007 standard [60]. 


\section{Table 1a. Polyurethane paint 1 characterization}

Polyurethane emulsion HP255

Solids content $(\%$ w/w): 32.7 (DIN 532 19)

Density $\left(\mathrm{g} . \mathrm{cm}^{-3}\right): 1.02$ (ASTM D-475)

Viscosity Ford Cup No 4 (s): 18 (ASTM D-1200)

Oil absorption of the pigment $\mathrm{TiO}_{2}$ (rutile) (g oil/100g of pigment): 24 (ASTM D-281)

Paint composition obtained from applying high dispersion speed

Pigment content (\%): 15.75

Emulsion solids content (polyurethane polymer) (\%): 28.31

Rheological additive (\%): 0.30

Coalescent (\%): 0.11

Water $\left(\mathrm{cm}^{3}\right)$ : c.s.p. 100

Liquid paint

Density $\left(\mathrm{g} . \mathrm{cm}^{-3}\right): 1.05$

Solids content $(\% \mathrm{v} / \mathrm{v}): 30.76$

Pigment volume concentration (PVC): 12.20

Paint yield to obtain $100 \mu \mathrm{m}$ thickness $\left(\mathrm{m}^{2} \cdot \mathrm{L}^{-1}\right): 3$

Stormer viscosity at $20^{\circ} \mathrm{C}$ (UK): 75

Curing temperature $\left({ }^{\circ} \mathrm{C}\right): 23 \pm 2$ for 7 days

Applying method: by manual brushing

\section{Table 1b. Polyurethane paint 2 characterization}

Polyurethane emulsion HP255/A

Solids content (\% w/w): 35.4 (DIN 532 19)

Density (g. $\left.\mathrm{cm}^{-3}\right)$ : 1.05 (ASTM D-475)

Viscosity Ford Cup No 4 (s): 20 (ASTM D-1200)

Oil absorption of the pigment $\mathrm{TiO}_{2}$ (rutile) (g oil/100g of pigment): 24 (ASTM D-281)

Paint composition obtained from applying high dispersion speed

Pigment content (\%): 16.25

Emulsion solids content (polyurethane polymer) (\%): 31.20

Rheological additive (\%): 0.30

Coalescent (\%): 0.11

Water $\left(\mathrm{cm}^{3}\right)$ : c.s.p. 100

Liquid paint

Density (g.cm-3): 1.09

Solids content $(\% \mathrm{v} / \mathrm{v}): 33.10$

Pigment volume concentration (PVC): 11.76

Paint yield to obtain 100 $\mu \mathrm{m}$ thickness (m2.L-1): 3

Stormer viscosity at $20^{\circ} \mathrm{C}$ (UK): 79

Curing temperature $\left({ }^{\circ} \mathrm{C}\right): 23 \pm 2$ for 7 days

Applying method: by manual brushing 


\section{Table 1c. Polyurethane paint 3 characterization}

Polyurethane emulsion HP1001

Solids content (\% w/w): 33.6 (DIN 532 19)

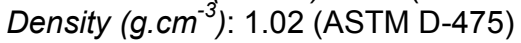

Viscosity Ford Cup No 4 (s): 18 (ASTM D-1200)

Oil absorption of the pigment $\mathrm{TiO}_{2}$ (rutile) (g oil/100g of pigment): 24 (ASTM D-281)

Paint composition obtained from applying high dispersion speed

Pigment content (\%): 15.25

Emulsion solids content (polyurethane polymer) (\%): 28.47

Rheological additive (\%): 0.30

Coalescent (\%): 0.11

Water $\left(\mathrm{cm}^{3}\right)$ : c.s.p. 100

Liquid paint

Density $\left(\right.$ g. $\left.\mathrm{cm}^{-3}\right): 1.05$

Solids content $(\% \mathrm{v} / \mathrm{v}): 30.66$

Pigment volume concentration (PVC): 11.76

Paint yield to obtain $100 \mu \mathrm{m}$ thickness $\left(\mathrm{m}^{2} \cdot \mathrm{L}^{-1}\right): 3$

Stormer viscosity at $20^{\circ} \mathrm{C}$ (UK): 76

Curing temperature $\left({ }^{\circ} \mathrm{C}\right): 23 \pm 2$ for 7 days

Applying method: by manual brushing

\subsection{Morphology, Chemical and Structural Analysis}

The morphology of the ZHEX and ZTRI coatings was characterized by SEM using a Philip model SEM 505 with ADDAll system, while their chemical composition was analyzed by EDXS measurements with a Si detector and $20 \mathrm{keV}$ energy.

\subsection{Tests to which the Polyurethane Paint Films were Subjected}

The reported values obtained from measurements in dry and wet conditions are the average of five measurements carried out on replicates of the same sample types:

Adhesion: Adhesion measurements were carried out by the Tape Test method according to the ASTM D3359-09e2 standard (Test Method B) [61].

Porosity: It was determined according to the ASTM D5162-08 standard [62] by using the Elcometer 236 DC Holiday Detector; maximum applied voltage $=2500 \mathrm{~V}$.

Gloss and color: were respectively determined according to the ASTM D523-08 [63], and the ASTM D2244-09b [64] standards by using the BYK Gardner Spectro-Guide Sphere Gloss with $60^{\circ} \mathrm{C}$ of incidence angle.

Hardness: It was accomplished according to the ASTM D3363-05(2011) e2 standard [65].

Flexibility: The $3.2 \mathrm{~mm}$ mandrel (equivalent to $28 \%$ of elongation) was chosen to perform this test according to the ASTM D522-93a-2008 standard [66]. One layer of each PU paint was applied on pre-treated steel panels and kept in laboratory atmosphere ( $\mathrm{RH} 65 \pm 5 \%$ and $\left.23 \pm 2^{\circ} \mathrm{C}\right)$ for 7 days. 
Blistering and white rusting degrees: The size and frequency of blisters as well as the white rusting degree were evaluated according to the ASTM D-714-02 and ASTM D610/08 standards, respectively [67].

\subsection{Electrochemical Behavior}

The shielding performance of each coating applied on the steel sheets and subjected to continuous immersion in open to air $0.05 \mathrm{M} \mathrm{NaCl}(\mathrm{pH} 5.70)$ or $0.1 \mathrm{M} \mathrm{Na}_{2} \mathrm{SO}_{4}(\mathrm{pH}$ 6.36) solutions was studied by EIS measurements. These were carried out using a conventional electrochemical cell with the three-electrodes arrangement: a Pt-Nb mesh with negligible impedance acting as counter electrode, a Saturated Calomel Electrode (SCE) as reference electrode and the working electrode was the coated steel sample, placed horizontally looking upwards at tha bottom in a flat-cell configuration. The electrolytes were confined in glass tubes attached to the working electrode by an o-ring defining a nominal testing area = $15.9 \mathrm{~cm}^{2}$. All the measurements were performed at room temperature $\left(22 \pm 3^{\circ} \mathrm{C}\right)$.

Impedance spectra in the frequency range $10^{-2}<\mathrm{f}(\mathrm{Hz})<10^{5}$ were obtained, in the potentiostatic mode at the free corrosion potential $\left(E_{\text {corr }}\right)$, as a function of the immersion time in the electrolyte solutions using a Solartron $1255 \mathrm{FRA}^{\circledR}$ coupled to an Impedance Potentiostat-Galvanostat Omnimetra PG-19A ${ }^{\circledR}$ and both controlled by the ZPlot ${ }^{\circledR}$ program. The rms width of the sinusoidal voltage signal applied to the system was $8 \mathrm{mV}$ and 10 points per decade were registered. The experimental spectra were fitted to model equivalent electrical circuits by using the Boukamp software [68] and the circuit components were associated to physicochemical process occurring in the system. All impedance measurements were executed with the electrochemical cell inside a Faraday cage to reduce external interferences as much as possible. The samples integrity was checked by measuring the corrosion potential after all the tests to confirm that the change from the initial value was no higher than $\pm 5 \mathrm{mV}$.

Taking into account that the corrosion behavior of passivated, painted and/or multi coated materials strictly depends on the production procedure; all the tests were carried out on three replicates of each sample type. The experimental results reported in the following Tables and Figures are the average of those obtained in each case.

\section{RESULTS AND DISCUSSION}

\subsection{Conversion Layer Characterization}

The thickness and description of the metallic protective coating (zinc + conversion layer) electrodeposited on the steel sheets used in this work are reported in Table 2. The conversion layer thickness was evaluated breaking the samples in liquid nitrogen and conducting the SEM analyses on the cross-section of ZTRI and ZHEX passivation layers. These were homogeneous and thin $(\approx 0.3 \mu \mathrm{m})$ throughout the entire surface; and their color was respectively clear grey and bright yellow. As well, the results presented in Table 2 allowed to infer that it was easier to form a conversion coating on zinc in the $\mathrm{Cr}^{+6}$ than in the $\mathrm{Cr}^{+3}$-containing bath since, with the half time of treatment, the thickness of the ZHEX passivation layer was almost equal than that of the ZTRI one.

Information related to coatings morphology after the coating/drying process is very important since the presence of flaws such as pores and/or other defects could be areas were a 
localized corrosion of the treated zinc surface starts from its exposure to a given environment [19,69-81]. The coatings surface morphology was observed at up to a maximum of 10,000X by SEM. As seen in Fig. 1a, the ZHEX coating deposited on the zinc surface shows structural failure and micro pores of irregular size. As well, Fig. 1c depicts that despite having a micro-rough surface and homogenous structure, the ZTRI samples also exhibited the characteristics cracks of chromate layers. According to previous reports [82-84] during the drying step of the conversion treatment, the chromium-based layer could shrink due to internal tensile stresses causing micro-cracks or fissures to develop, i.e., make it permeable to the zinc dissolution. This consideration is important because the bare ZHEX and ZTRI samples showed localized corrosion during the exposure to $0.05 \mathrm{M} \mathrm{NaCl}$ or $0.1 \mathrm{M}$ $\mathrm{SO}_{4} \mathrm{Na}_{2}$ solutions.

On the other hand, while the EDXS analysis did not detect Fe (substrate) in ZHEX samples (Fig. 1b) and less than $0.5 \%$ in ZTRI samples (Fig. 1d), results reported in Table 2 confirmed not only that the $\mathrm{Cr}$ distribution was homogeneous on the entire surface but also that its content was higher in the ZHEX than in the ZTRI samples. The gold peak in Figs. $1 \mathrm{~b}$ and $1 \mathrm{~d}$ was due to the samples metallization.

Table 2. Identification, description and thickness of the bare electrogalvanised tested samples

\begin{tabular}{lllllll}
\hline Samples & Description & $\begin{array}{l}\text { Average Cr-content } \\
(\mathbf{\%})\end{array}$ & & $\begin{array}{l}\text { Average } \\
\text { thickness of the } \\
\text { conversion layer } \\
(\mu \mathrm{m})\end{array}$ & $\begin{array}{l}\text { Average } \\
\text { thickness of } \\
\text { the zinc }+ \\
\text { conversion } \\
\text { layers }(\boldsymbol{\mu m})\end{array}$ \\
\hline ZHEX & $\begin{array}{l}\mathrm{Zn}+\mathrm{Cr}^{6+} \text {-based } \\
\text { conversion treatment }\end{array}$ & 2.51 & 2.50 & 2.55 & 0.3 & $11.74 \pm 1.16$ \\
\hline $\mathbf{Z T R I}$ & $\begin{array}{l}\mathrm{Zn}+\mathrm{Cr}^{3+} \text {-based } \\
\text { conversion treatment }\end{array}$ & 1.28 & 1.42 & 1.30 & 0.3 & $10.11 \pm 1.44$ \\
\hline
\end{tabular}

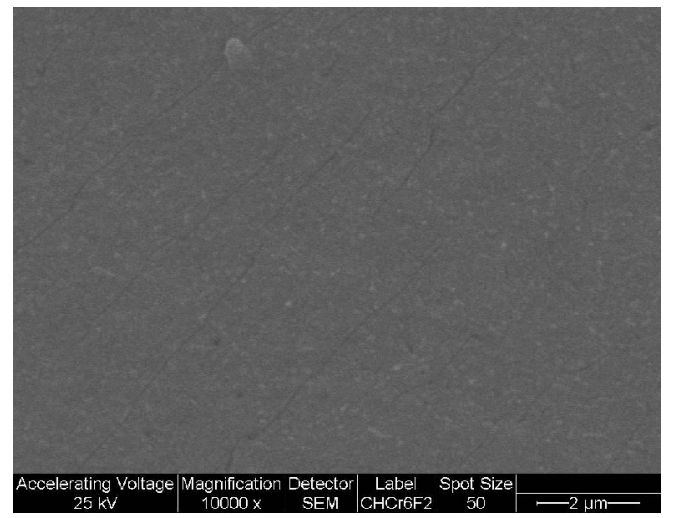

(a)

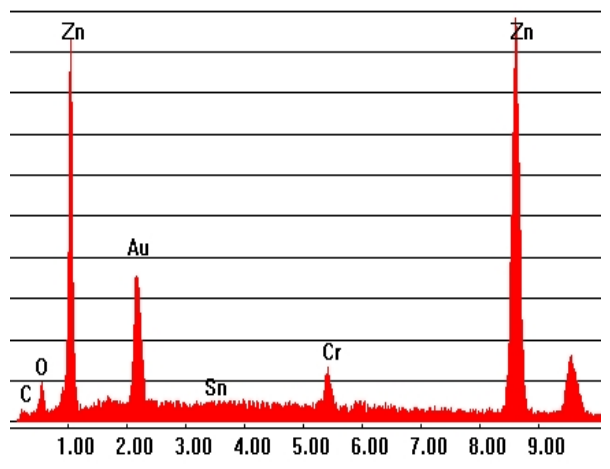

(b) 


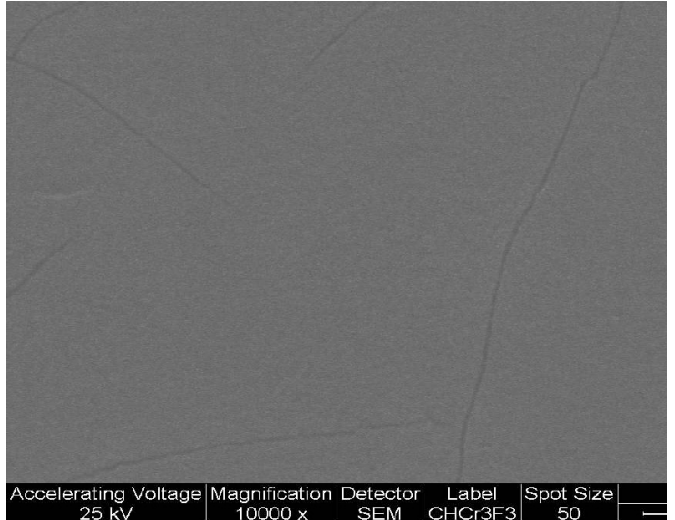

(c)

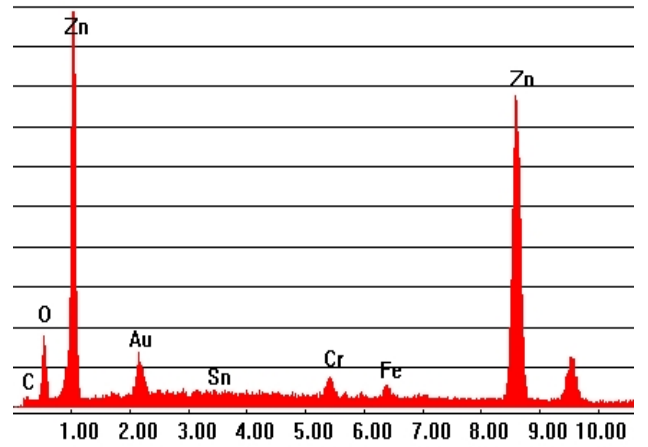

(d)

Fig. 1. (a) SEM micrograph, (b) EDXS profile of the ZHEX samples, (c) SEM micrograph and (d) EDXS profile of the ZTRI samples. Magnification: 10,000X

\subsection{Duplex System Characterization}

\subsubsection{Results of the standardized tests carried out on the applied barrier polyurethane paints before and after 94 days of immersion in the electrolytes}

Barrier properties of the painting systems are of great interest, since they determine the water transport and/or dissolution and supply of pigments to the metal substrate. Water permeability and ionic diffusion as well as corrosion potential and impedance measurements provide insight related with those organic coating properties. In such sense the heterogeneous nature of the electrical properties of polymeric films is physically represented like an also heterogeneous group of electrolitically conducting paths. Thus, in localized areas, the coating does not behave like a dielectric but shows an electrolytic conductivity due to electrolyte dissolution inside the structural defects of the polymer or because of its penetration through the film pores. In other localized regions, the coating has the properties of a relatively inert dielectric material. At the metal/organic coating interface, several complex processes of difficult interpretation may take place since after the co rodents $\left(\mathrm{H}_{2} \mathrm{O}, \mathrm{O}_{2}\right.$ and ionic species) permeation different electrochemical reactions are possible $[85,86]$.

When painted and pre-treated steel plates are submerged in an aqueous solution, the water absorbed by the organic coating can dissolve some pigments. It is known that a high barrier effect or a low diffusion of corrosion inhibiting species can keep or accelerate the active state even if there is a significant pigment content in the paint film. Thus it is difficult to determine whether the metallic substrate is passivated or not, particularly in the presence of anions like $\mathrm{Cl}^{-}$, which are capable of breaking the passivation layer [87-89]. This can be only balanced either by increasing the minimum PVC required to obtain such layer $[86,90]$ and/or the paint film barrier properties using a properly chosen painting system.

As the coating under study was a barrier protective topcoat it would, in service form the outer layer of a painting system consisting also of an anticorrosive primer and depending on the exposure conditions aggressiveness, an intermediate layer. For that reason, to elucidate correctly the protective scheme able to withstand long time a given exposure condition, it is necessary to know not only the effectiveness of the passivated electrogalvanised steel/painting system but as well which would be the contribution of each layer to the overall 
protective effect. As part of the efforts carried out for solving this problem, the protective effect offered by three barrier polyurethane paints against the corrosion of electrogalvanised

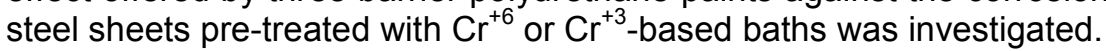

\subsubsection{Paint film thickness}

Each bare ZHEX or ZTRI sample was covered with two coats of the Paint 1, Paint 2 or Paint 3 polyurethane $\left(\mathrm{PU}_{\mathrm{i}}\right)$ topcoat formulation (Table 1a-1c), whose average dry overall thickness, measured according to the ISO 2808-2007(2010) standard was $140 \pm 7 \mu \mathrm{m}$.

\subsubsection{Porosity}

Its evaluation was made according to the ASTM D-5162-08 standard. All the replicates with no pinhole detected at $2500 \mathrm{~V}$ were used. At the end of the test, the exposed samples were newly inspected and no pinhole was detected. This means that the entire surface of the paint film structure exhibited a suitable continuity, which was not modified by immersion in $\mathrm{Na}_{2} \mathrm{SO}_{4}$ or $\mathrm{NaCl}$ solutions for 94 days.

\subsubsection{Blistering and white rusting degrees}

Blistering and/or White corrosion are signs of the breakdown in the coatings protective nature. They were evaluated according to the ASTM D-714-02(2009) and ASTM D-61008(2012) standards, respectively. The visual inspection results corresponding to replicates of the painted ZHEX and ZTRI samples suggested that an effective corrosion inhibitive action was developed by the conversion layer $+\mathrm{PU}_{i}$ coatings. Shown in Fig. 2 for some samples (similar trend was also observed for the other ones not included here), the visual evidence allowed to assume that, at least from this highly subjective qualification mode, after 94 days of exposure to aerated $0.1 \mathrm{M} \mathrm{Na}_{2} \mathrm{SO}_{4}$ or $0.05 \mathrm{M} \mathrm{NaCl}$ solutions, no sample was affected by blistering or white rusting. As a result, according to the established by the respective standards, the qualification for both surface aspects was 10 .

\subsubsection{Gloss and color}

Evaluated according to the guidelines of the ASTM D-523-08 standard, the Gloss measurements at $60^{\circ}$ angle of observation performed before and after the immersion test did not show noticeable changes. The average values, respectively 85 and 81.2 , indicated that the paint film behaved as a gloss of perfect white diffuser. Since this property is associated to the smoothness of the paint film, the slight darkening was probably due to small changes of the polyurethane surface texture because of electrolyte-paint interactions occurred during the test [25]. As well, the color (ASTM D-2244-09b standard) of the $\mathrm{PU}_{\mathrm{i}}$ films did not show any change in its chromaticity values.

\subsubsection{Hardness}

The PUi films hardness was evaluated according to ASTM D-3363-05(2011) e2 standard, i.e. in terms of pencils leads of known hardness. Before and after the immersion test in aerated $0.1 \mathrm{M} \mathrm{Na} 2 \mathrm{SO} 4$ or $0.05 \mathrm{M} \mathrm{NaCl}$ solutions for 94 days, the measurements gave values harder than $6 \mathrm{H}$, which specified paints film classified as hard [25]. The maintenance of this property even though elapsed the continuous immersion was attributed to the 
combined effect of the high cross linking attained during the polyurethane curing process, the strong bonding among the cross linked chains and the lack of paint films defects.
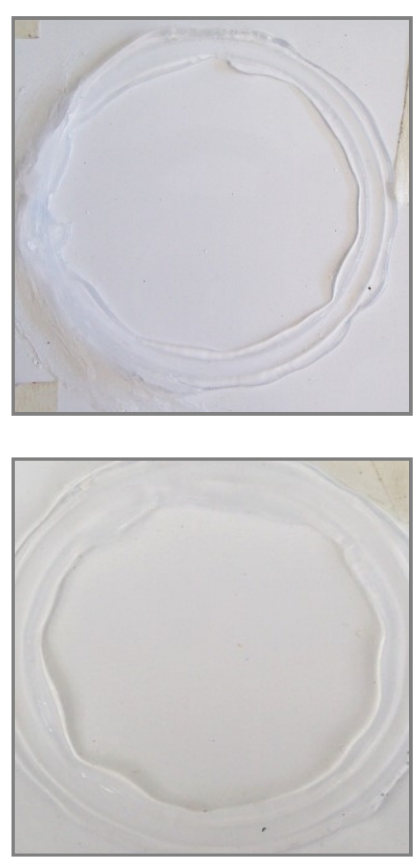

PAINT 1

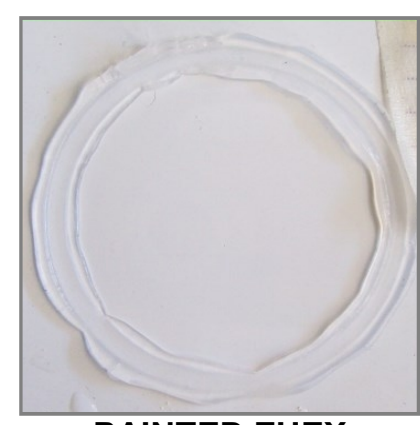

PAINTED ZHEX

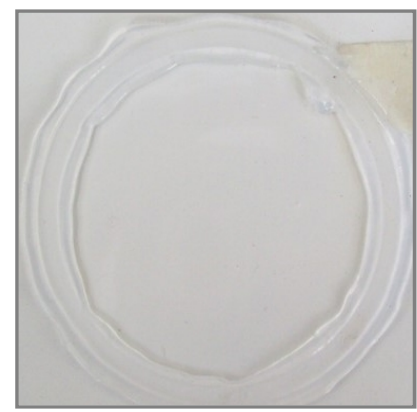

Paint 2
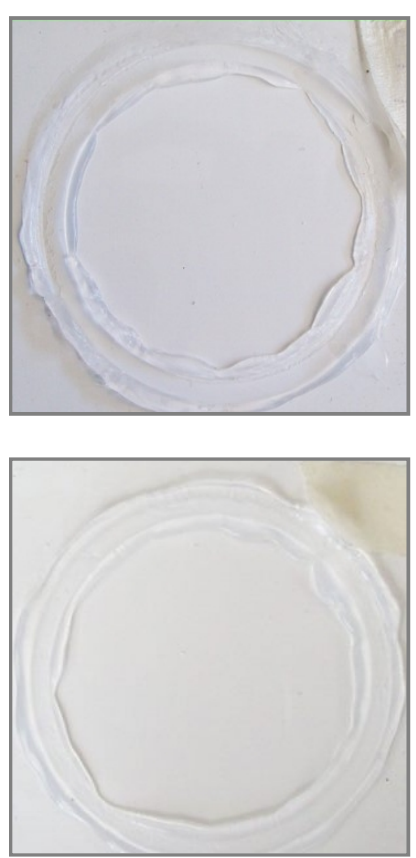

Paint 3

Fig. 2. Photographs of the surface state of $P U_{i}$ paint/ZHEX or ZTRI samples after removing the acrylic cell

\subsubsection{Flexibility}

The evaluation of the paint films flexibility took place according to the ASTM D-522-93a-2008 standard. The painted samples immersed in $0.1 \mathrm{M} \mathrm{Na}_{2} \mathrm{SO}_{4}$ or $0.05 \mathrm{M} \mathrm{NaCl}$ solutions for 94 days produced important changes in the paint films stiffness. Before the immersion, the $\mathrm{PU}_{i}$ paint films behaved satisfactorily in this test since after bending no cracking, checking or flaking was observed but at the end of the exposure, those underwent cracking. The increase of the paint film stiffness was probably due to the diffusion of low molecular weight water-soluble components, which originally served to plasticize the coating, towards the paint/electrolyte interface. As a result, the paint film became brittle.

\subsubsection{Adhesion}

The common way to analyze adhesion loss of coating films from a substrate is according to ASTM D-3359-09e2 standard, method B (cross-cut tape test) [61]. Different studies have shown that in many cases the loss of adhesion is coincident with the presence of water at the metal/coating interface $[49,91,92]$. In the rather qualitative tape-test the scales used by this standard to classify the specimens is from $\mathrm{OB}$ to $5 \mathrm{~B}$, where $\mathrm{OB}$ corresponds to a very poor (percent of area removed greater than $65 \%$ ) and $5 \mathrm{~B}$ to a very good adhesion (percent of area removed $0 \%$ ), respectively.

After 7 days of curing, the adhesion of the $P U_{i}$ paints to the ZHEX and ZTRI samples was examined by means of the destructive tape-test, while replicates of those were immersed in 
$0.05 \mathrm{M} \mathrm{NaCl}$ or $0.1 \mathrm{M} \mathrm{SO}_{4} \mathrm{Na}_{2}$ solutions for 94 days. At the end of this period, the tested panels were inspected and classified.

Table 3 shows the tape-test results obtained with the painted ZHEX and ZTRI samples before and after the immersion test. As seen, in both cases and regardless of the applied pretreatment, the adhesion properties classification for the barrier $\mathrm{PU}_{i}$ topcoats was from almost null (OB) to rather poor (3B) not only at the center and edges of the samples but also inside and outside of the cell. This, in general, severe lack of adhesion at the paint/pretreatment interface could be attributed to the fact that the very smooth profile of the pretreated galvanized steel surfaces suggests the formation of few and weak adhesive bonds at the polymer/metal interface, which led to the scarce adhesion between the paint and the conversion layer surface. From this result was inferred that the surface should be roughened to improve paint adhesion but such a treatment was disabled by the extremely thin thickness $(0.3 \mu \mathrm{m})$ of the conversion layer, factor that by itself limits its protective properties [93,94]. As well, the Table 3 reveals that in the case of PU1 and PU3 exposed to the $\mathrm{Cl}^{-}$solution and the PU2 in contact with the $\mathrm{SO}_{4}^{-2}$ solution a slight adhesion improvement was found. Such an effect was ascribed to the development of chemical bonds between the polymer layer and the pretreated zinc surface during the immersion test due to an increase of surface roughness and hence the number of active centers, caused by localized corrosion processes did not detect by the naked eye. Once the paint films were entirely removed, a small amount of white corrosion products clearly visible on the metallic surface of those samples confirmed that hypothesis.

Table 3. Results from the ASTM D 3359 dry and wet adhesion tests for the topcoat polyurethane paints applied on ZHEX or ZTRI samples

\begin{tabular}{|c|c|c|c|c|c|c|c|c|c|}
\hline \multirow[t]{3}{*}{ Sample } & \multirow{2}{*}{\multicolumn{3}{|c|}{ Dry adhesion }} & \multicolumn{6}{|c|}{ Wet adhesion } \\
\hline & & & & \multicolumn{2}{|c|}{$0.1 \mathrm{M} \mathrm{Na}_{2} \mathrm{SO}_{4}$} & \multicolumn{4}{|c|}{$0.05 \mathrm{M} \mathrm{NaCl}$} \\
\hline & PU 1 & PU 2 & PU 3 & PU 1 & PU 2 & PU 3 & PU 1 & PU 2 & PU 3 \\
\hline ZHEX & 3B & OB & OB & 1B & OB & OB & OB & OB & OB \\
\hline ZTRI & $2 \mathrm{~B}$ & $O B$ & $\mathrm{OB}$ & $\mathrm{OB}$ & $3 B$ & 1B & $2 B$ & 1B & $O B$ \\
\hline
\end{tabular}

Classification of adhesion test results according to the ASTM D 3359/09e2 standard

\begin{tabular}{lllllll}
\hline Classification & 5B & 4B & 3B & 2B & 1B & 0B \\
\hline Percent of Area & 0\% None & Less than $\%$ & $5-15 \%$ & $15-35 \%$ & $35-65 \%$ & Greater than $65 \%$ \\
\hline
\end{tabular}

Despite this unexpected difficulty, the study went on due to features such as: (1) for attaining a good compatibility at the metal/coating interface, it is important to understand the characteristics of all the types of paint that will be used; (2) each formulated paint exhibits unique characteristics that can affect its suitability to be used with either or not pretreated galvanized steel. Therefore as more details about the interactions between the coating layers are available, higher is the chance of formulating the best coating system for each practical situation and (3) the fact that in practice, such lack of adhesion can be overcome by applying a primer that being fully compatible with both the metallic substrate and the topcoat paint allows to compose a successful duplex system. 


\subsection{Electrochemical Evaluation}

\subsubsection{Impedance spectra of the bare pre-treated galvanized steel}

At first sight, a comparative analysis performed based on the Nyquist diagrams shown in Fig. 3 for the bare ZHEX and ZTRI samples immersed into naturally aerated $0.1 \mathrm{M} \mathrm{Na}_{2} \mathrm{SO}_{4}$ or $0.05 \mathrm{M} \mathrm{NaCl}$ solutions would allow to infer that the ZHEX samples were the most corrosion resistant in both electrolytes. The same Figure also shows that at the beginning ( $t=0$ day) of the exposure to both solutions, the Nyquist plots of the bare ZHEX and ZTRI samples showed, in general, two time constants $\left(\mathrm{T}_{\mathrm{i}}\right)$ more or less well defined. Then, as the exposure time elapsed, they tended to overlap entirely indicating that the relaxation time of the processes associated to them took place at or nearly the same time and as a result, only one semicircle could be observed. However as it will be latterly discussed, each one of these semicircles could contain more than one time constant since they overlapped when $\mathrm{T}_{\mathrm{i}} / \mathrm{T}_{\mathrm{i}+1}<5$ [95].
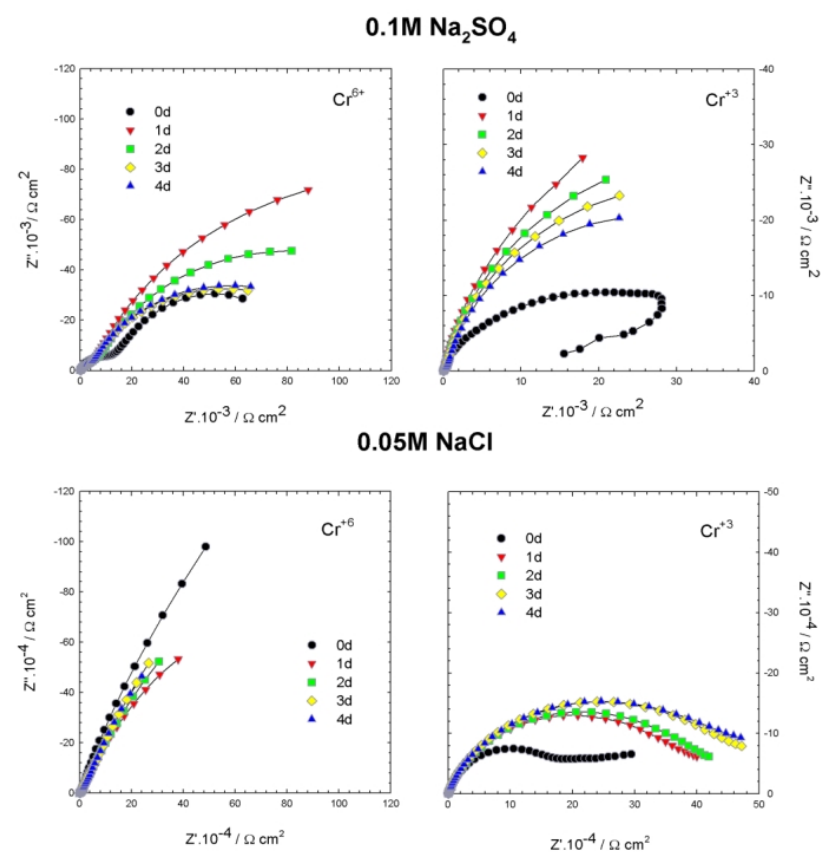

Fig. 3. Representative Nyquist diagrams of the bare ZHEX or ZTRI samples immersed in aerated $0.1 \mathrm{M} \mathrm{Na}_{2} \mathrm{SO}_{4}$ or $0.05 \mathrm{M} \mathrm{NaCl}$ solutions.

\subsubsection{Impedance spectra of the painted pre-treated galvanized steel (duplex system) samples immersed in $0.1 \mathrm{M} \mathrm{Na}_{2} \underline{\mathrm{SO}}_{4}$ or $0.05 \mathrm{M} \mathrm{NaCl}$}

Considering the unsatisfactory corrosion behavior of the electrogalvanised steel sheets after being pretreated, the EIS spectra for the three tested duplex systems immersed in $0.1 \mathrm{M}$ $\mathrm{Na}_{2} \mathrm{SO}_{4}$ or $0.05 \mathrm{M} \mathrm{NaCl}$ solutions were obtained. A typical evolution of these data performed based on Nyquist diagrams is depicted in Figs. 4 and 5 for selected exposure times. At the initial stages, such diagrams show very large slopes, which were almost vertical to the horizontal axis for all the samples, regardless of the paint formulation. At longer immersion times, the impedance spectra remained almost overlapped indicating that the duplex protective systems stayed at high impedance values even after 94 days of test in contact 
with both electrolytes. The total impedance for all the painted ZHEX and ZTRI samples were great than $10^{8} \Omega \mathrm{cm}^{2}$. Therefore, the obtained electrochemical results confirmed that the overall coatings were good shielding layers with large impedance and the metallic substrate was protected well throughout the immersion tests $[13,96,97]$.

\section{$0.1 \mathrm{M} \mathrm{Na}_{2} \mathrm{SO}_{4}$}
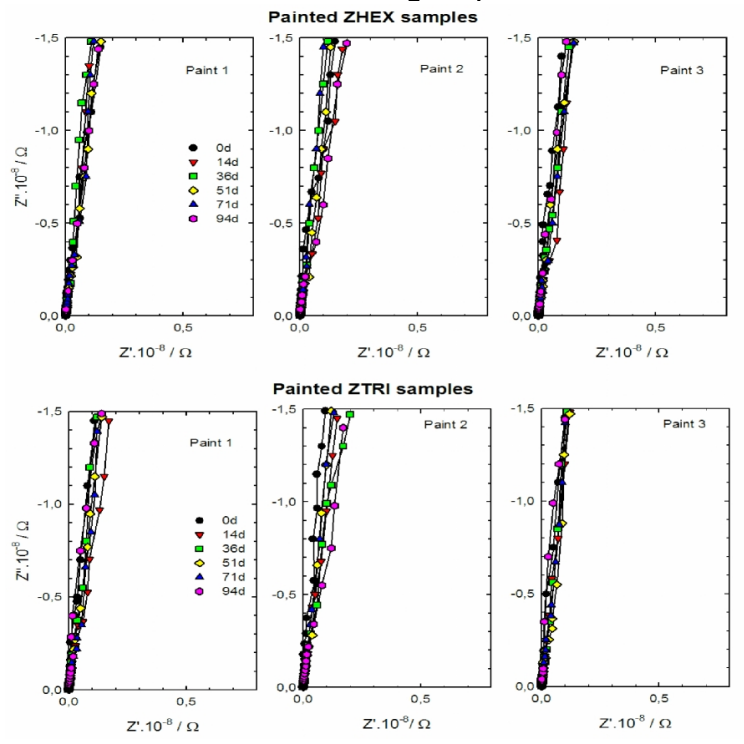

Fig. 4. Representative Nyquist diagrams of the painted ZHEX or ZTRI samples immersed in aerated $0.1 \mathrm{M} \mathrm{Na}_{2} \mathrm{SO}_{4}$ solution.

$0.5 \mathrm{M} \mathrm{NaCl}$

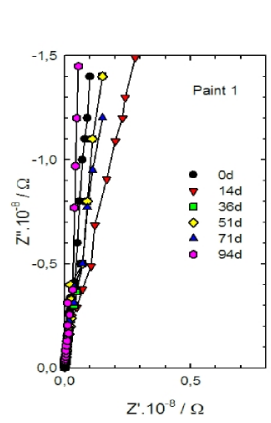

Painted ZHEX samples
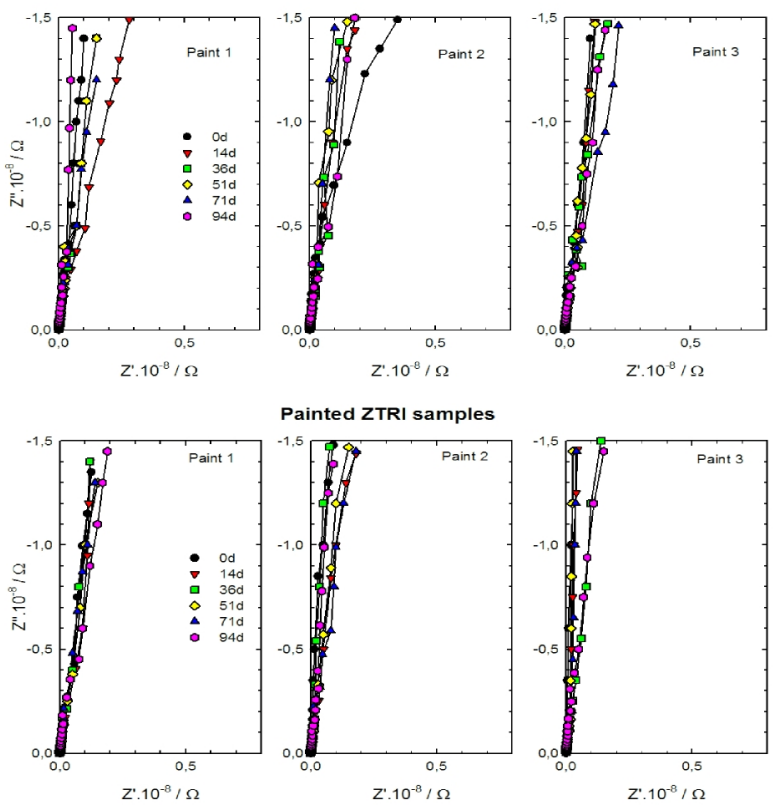

Fig. 5. Representative Nyquist diagrams of the painted ZHEX or ZTRI samples immersed in aerated $0.05 \mathrm{M} \mathrm{NaCl}$ solution. 


\subsubsection{Equivalent circuit}

In order to interpret the impedance data for both types of samples, the most probable equivalent circuit [68] able to model those data is shown in Fig. 6. The algorithm involving the transfer function derived from this circuit was given by:

where:

$$
Z(\omega)=R+\frac{R_{1}}{\left(j \omega R_{1} C_{1}\right)^{\alpha 1}+\frac{1}{1+Z_{2} / R_{1}}}
$$

$$
Z_{2}(\omega)=\frac{R_{2}}{\left(j \omega R_{2} C_{2}\right)^{\alpha 2}+1}
$$

and

$\mathrm{R}=$ electrolyte resistance between the reference and working (coated steel) electrodes.

$\mathrm{j}=\sqrt{-1}$

$\omega=2 \pi \mathrm{f}=$ angular frequency.

$0<\alpha_{i} \leq 1$ = Cole-Cole parameters [87] modeling the dispersion of both time constants.

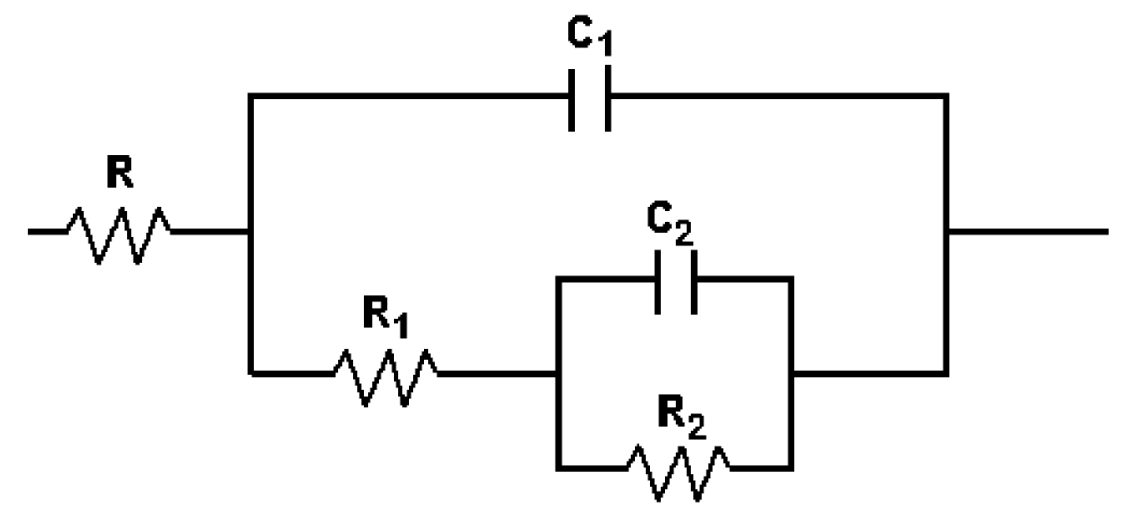

Fig. 6. Equivalent circuit used for fitting either the bare or the painted ZHEX or ZTRI samples subjected to the immersion test.

As seen, this circuit was based on two contributions, $\left(R_{1} C_{1}\right)$ and $\left(R_{2} C_{2}\right)$, related to high and low frequency time constants, respectively. According to the studied system, these time constants get different physical meaning. In the case of the bare ZHEX and ZTRI samples, $R_{1}$ and $C_{1}$ were associated to the conversion layer impedance represented by the resistive $\left(R_{c}\right)$ and capacitive $\left(C_{c}\right)$ elements, while the impedance at the lower frequency range was related to the zinc dissolution reaction where $R_{c t}$ represented the charge transfer resistance coupled to the electrochemical double layer capacitance $\left(C_{d 1}\right)$. The more interesting data to discuss are the chromate pretreatment resistance $\left(R_{c}\right)$, which gives information about the barrier properties of the conversion layer and the charge transfer resistance $\left(R_{c t}\right)$ given information on the zinc corrosion process kinetic. For the duplex system, the $\mathrm{R}_{1} \mathrm{C}_{1}$ time constant was related to the dielectric properties of the paint film, the conversion layer and the corrosion products generated at the conversion layer/zinc interface. The low frequency time constant was associated to the zinc corrosion process; so that $R_{2}$ represented the charge transfer resistance and $\mathrm{C}_{2}$ the electrochemical double layer capacitance.

Difficulties in providing an accurate physical description of the occurred processes are sometimes found. In such cases a standard deviation value $\left(\chi^{2}<5 \times 10^{-4}\right)$ between 
experimental and fitted impedance data was used as final criterion to define the "most probable circuit".

\subsection{Time Dependence of the Resistive Elements Contributing to the Bare ZHEX and ZTRI Samples Impedance}

The results obtained from the fitting procedure described in the above paragraph are shown in Fig. $7 a$, which depicts the $\mathrm{R}_{c}$ evolution for the bare ZHEX and ZTRI samples as a function of the immersion time in both electrolytes. In it can be seen that, during the 4 days of immersion in the $\mathrm{Na}_{2} \mathrm{SO}_{4}$ solution, the $\mathrm{Cr}^{6+}$-based pretreatment offered to the underlying zinc layer a slightly great barrier protection than the $\mathrm{Cr}^{3+}$-one, but also that the same did not occur with their replicates in contact with the $\mathrm{NaCl}$ solution. This discrepancy was interpreted in terms of the role played by the barrier to the corrosive agents diffusion provided mainly by the thin conversion layer itself and the zinc corrosion products developed during the test. Initially, the barrier resistance was related to the physical barrier between the zinc and the electrolyte due to the presence of both the conversion layer and the native oxides that always exist on the very reactive zinc surfaces [98-100].
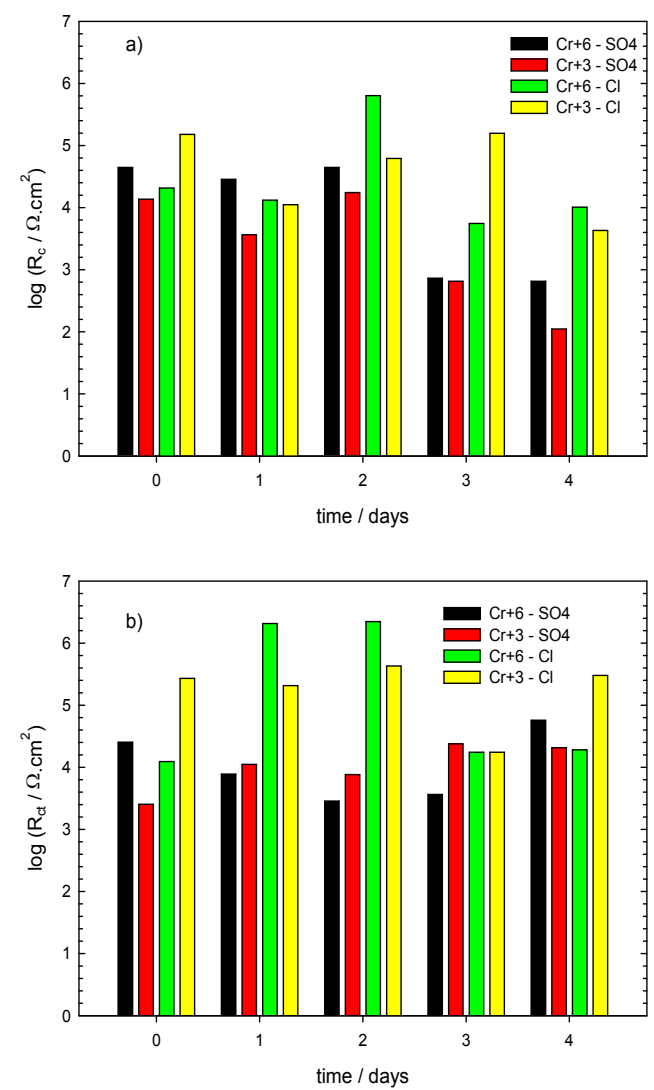

Fig. 7. Time dependence of (a) $\log R_{c}$ and (b) Log $R_{c t}$ parameters for the bare ZHEX or ZTRI samples immersed in aerated $0.1 \mathrm{M} \mathrm{Na}_{2} \mathrm{SO}_{4}$ or $0.05 \mathrm{M} \mathrm{NaCl}$ solutions.

Then, when the electrolyte reached the zinc layer at the bottom of the pre-treatment pores and/or micro-cracks and after a certain activation period [101], those oxides dissolved and 
the zinc localized corrosion started to develop [102] with a kinetic dependence on the electrolyte aggressiveness. From this situation, the barrier resistance evolution was attributed to different contributions. So, in the case of ZHEX samples, the passive layer deterioration or loss could, within the limits fixed by the concentration of mobile $\mathrm{Cr}^{6+}$ species able to diffuse to any defect in the conversion layer, be compensated by the self-healing action provided by these mobile $\mathrm{Cr}^{6+}$ species and/or the accumulation of zinc corrosion products (acting partially as a barrier limiting the access of the reactants to the zinc substrate) within and/or at the bottom of the conversion layer defects. As in the ZTRI samples the self-healing effect could not take place due to the lack of $\mathrm{Cr}^{6+}$-free ions, either the diminishing or increasing of the $\mathrm{R}_{\mathrm{c}}$ values depended mostly on the corrosion products behavior. Therefore, being absent the self-healing effect and taking into account the $\mathrm{Cl}^{-}$ion capacity of breaking faster the passive layer, it is reasonable that the effect of the zinc corrosion products on the conversion layer barrier resistance value was much more significant in the solution test containing this anion than in that with the $\mathrm{SO}_{4}{ }^{2-}$ one.

In Fig. $7 b$ it is possible to note that the $R_{\text {ct }}$ values for the bare ZHEX and ZTRI samples had also an oscillating behavior at increasing the immersion time. In the case of the ZHEX samples, this trend could be due to the zinc dissolution reaction in the structural micropores of the pre-treatment layer was influenced by the passivation-depassivation action, respectively exerted by the solubilization of the $\mathrm{Cr}^{6+}$-free ions in the conversion layer and the anion $\left(\mathrm{SO}_{4}{ }^{2-}\right.$ or $\left.\mathrm{Cl}^{-}\right)$in the electrolyte, added to the accumulation-diffusion of the zinc corrosion products at or from the same defects. However, such passivation, absent in the completely insoluble in water $\mathrm{Cr}^{3+}$-based pretreatments due to the lack of free- $\mathrm{Cr}^{6+}$ ions in the conversion layer structure made that, once lost the surface passivation of the ZTRI samples, the increase or decrease of the $R_{c t}$ values as a function of the immersion time was attributed only to the corrosion products accumulation at- or diffusion from- the conversion layer defects. The conclusion that can be obtained from this part of the work is that the layer of the tested thin pretreatments offered low barrier properties and therefore low corrosion protection. As well that the obtained differences were not enough to provide evidence that the $\mathrm{Cr}^{3+}$-based pretreatment was better than the $\mathrm{Cr}^{6+}$ but they have made possible to report that the performance was at least, comparable.

\subsection{Time Dependence of the Resistive Elements Contributing to the Painted ZHEX and ZTRI Samples Impedance}

Fitted by the equivalent circuit shown in Fig. 6 and analyzed by the Boukamp software EQUIVCRT, the resistive $\left(R_{1}, R_{2}\right)$ components of the impedance corresponding to each duplex system (painted ZHEX and ZTRI samples) immersed into naturally aerated $0.1 \mathrm{M}$ $\mathrm{Na}_{2} \mathrm{SO}_{4}$ or $0.05 \mathrm{M} \mathrm{NaCl}$ solutions are shown in Fig. $8 \mathrm{a}-8 \mathrm{~d}$ and $8 \mathrm{e}-8 \mathrm{~h}$ respectively, for selected exposure times.

The coatings resistance $R_{1}$ reflects the electrolyte ability to diffuse through those and for that reason, it is used to evaluate the coating protective properties [103]. In the present case and from the electrical point of view, all the tested duplex systems had actually three resistive layers in series, zinc passive + pretreatment + paint ones, from the beginning. The combination of three resistors in series results in higher overall values than the individual one. Consequently, the estimated $R_{1}$ values were related to the resistive properties of the zinc passive layer, the pretreatment layer and the paint film previously generated.

By comparing the Figs. $7 \mathrm{a}$ and $8 \mathrm{a}, 8 \mathrm{~b}, 8 \mathrm{e}$ and $8 \mathrm{f}$ can be seen that for the bare ZHEX and ZTRI samples, the $R_{c}$ values ranged $1.10^{2}-6.10^{5} \Omega \mathrm{cm}^{2}$ while for the painted ZHEX and ZTRI samples the overall coating resistance $\left(R_{1}\right)$ was about $10^{7}-10^{8.5} \Omega \mathrm{cm}^{2}$, i.e. at least 
two orders of magnitude greater than the bare samples. As a result, the overall resistance of the painted samples was dominated by the paint contribution, whose constant trend suggested that the duplex protective system maintained effective barrier properties for the 94 days of immersion without the creation of new defects [104-106]. This was ascribed to the fact that the dense and highly crosslinked structure made that the resistive properties were kept by the polyurethane paints throughout the test period. As a general hypothesis, it was assumed that the relative stability of the $\mathrm{R}_{1}$ values was mainly due to that neither the specific conductivity nor the geometric area related to the polyurethane films structure suffered significant changes of magnitude along the test [107]. Such results indicate that both the binder structural and chemical composition play a vital role with regard to the protection of the ZHEX and ZTRI samples because of their contribution to improve the coating resistance to water and matter transport. In addition, the high dielectric properties of the polyurethane paints $\left(C_{1} \cong 10^{-10}-10^{-12} \mathrm{Fcm}^{-2}\right.$ not shown here $)$ justifies that only two time constants were observed during the long immersion time and that associated with the protective action of the conversion layer did not change significantly during that period, as it corresponds to an effective barrier layer.

For the three duplex systems were not possible to distinguish the second time constant $\left(\mathrm{R}_{2} \mathrm{C}_{2}\right)$ by naked eye. In such situation, the existence of this overlapped time constant was put in evidence through the deconvolution of the impedance spectra by means of the fitting spectra.

The time dependence of the charge transfer resistance $R_{2}$ associated to the zinc dissolution reaction occurring at the bottom of the overall coating conductive pathways is reflected in Fig. 8c, 8d, 8g, 8h. As seen, all the tested samples showed an induction period before the corrosion process could be deconvoluted from the impedance spectra. Such induction period would be associated to the capacity of each paint film for delaying the hydrolysis at the zinc/coating interface as well as the corrosion inducing species arrival at this latter with the consequent formation of the electrochemical double layer and activation of the zinc surface. The subsequent oscillations were ascribed to the gathering of zinc corrosion products at the bottom and within the coating defects, which not only diminished the electrochemically active areas but also make difficult the transport of corrosive species towards these areas. On the contrary, the formation of new electrolyte conducting micro paths in less protective areas of the overall coating areas caused an increase of such areas and accordingly, the corresponding decrease of $R_{2}$ values. However, as these latter were very high along the tests in both electrolytes, the $\mathrm{R}_{2}$ evolution gave an idea that the corrosion rate was very low in all the cases. With regard to the corrosion process extension, it was assumed that the same was negligible because considering that the specific electrochemical double layer capacity $\left(\mathrm{C}_{\mathrm{dl}}\right)$ for bare zinc is about $30.10^{-6} \mathrm{Fcm}^{-2}$ [108] and the average value of this parameter for the painted ZHEX and ZTRI samples was $\left(C_{2}\right) \cong 5.10^{-11} \mathrm{Fcm}^{-2}$, it was estimated that the electrochemically active area defined as:

$$
\mathrm{A}=\mathrm{C}_{2} / \mathrm{C}_{\mathrm{dl}}
$$

was about $1.7 \cdot 10^{-6} \mathrm{~cm}^{2}$, it is to say, $\cong 0,00001 \%$ of the whole coated area. 

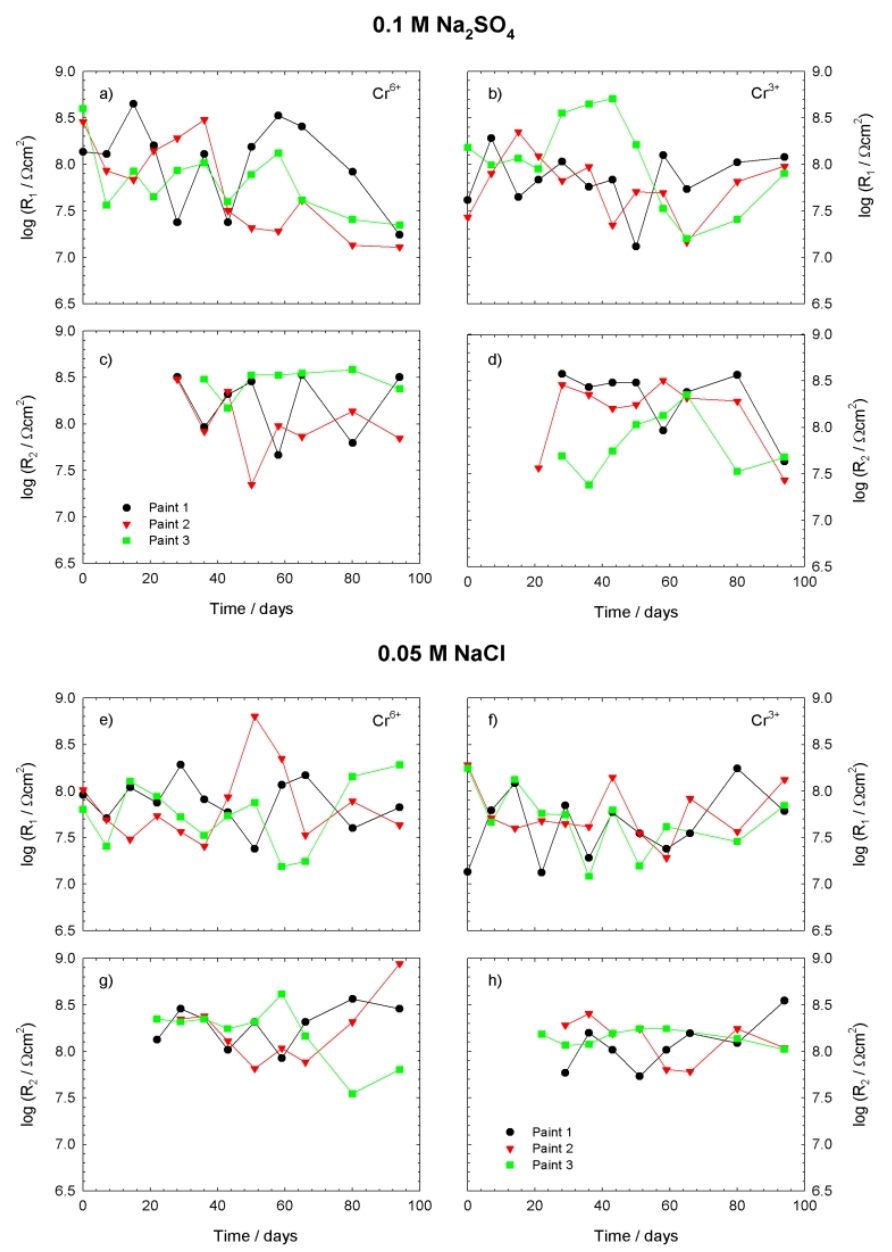

Fig. 8. Time dependence of $\log R_{1}$ and $\log R_{2}$ parameters for the $P U_{i}$ paint/ZHEX or ZTRI samples immersed in aerated. (a-d) $0.1 \mathrm{M} \mathrm{Na}_{2} \mathrm{SO}_{4}$ or (e-h) $0.05 \mathrm{M} \mathrm{NaCl}$ solutions.

\section{CONCLUSION}

From the results generated during this experimental work, the following main conclusions can be made with respect to the tested samples:

- With the half of the immersion time in the corresponding bath, the $\mathrm{Cr}^{6+}$-based conversion coating thickness was almost equal than that of the $\mathrm{Cr}^{3+}$ one;

- the different corrosion resistance of the two types of coatings was attributed to the availability of mobile, oxidizing $\mathrm{Cr}^{6+}$ species, which make possible the self-healing in defected areas;

- even though the experimental results indicated that the corrosion protection given by the $\mathrm{Cr}^{3+}$ treatment may not be as good as that given by the traditional $\mathrm{Cr}^{6+}$ treatment, the $\mathrm{Cr}^{3+}$ treatment may still be adequate for a wide variety of applications; 
- the very poor adhesion at the polyurethane paints-pretreated galvanized steel interface in both the ZHEX and ZTRI samples indicated the formation of few and weak adhesive bonds between the smooth pretreated zinc surface and the polymeric film;

- the anticorrosive performance of the different conversion layers either or not covered by the polyurethane paints and exposed to also different electrolytes was adequate and widely characterized by electrochemical techniques;

- although in some cases the effects of different processes overlapped, the impedance spectra afforded valuable information about the barrier properties of the paint films as well as on the pretreated zinc corrosion performance in $0.1 \mathrm{M} \mathrm{Na}_{2} \mathrm{SO}_{4}$ or $0.05 \mathrm{M} \mathrm{NaCl}$ solutions.

- The electrochemical performance of the duplex systems under immersion could be modeled using two RC time constants hierarchically distributed. The high frequency time constant, $\mathrm{R}_{1} \mathrm{C}_{1}$, was related to the dielectric properties of the paint + pretreatment + passive zinc layers for both systems. The low frequency time constant, $\mathrm{R}_{2} \mathrm{C}_{2}$, was associated to the zinc corrosion process;

- taking into account that the tested paints films only protected by barrier effect, and that the metal-paint adhesion was not the expected, the corrosion protection offered by the polyurethane-based polymeric films applied on pretreated electrogalvanised steel could be considered as acceptable;

All laboratory tests involved in this work were useful to characterize the bare or painted metallic surface since they allowed understanding the behavior of the studied systems subjected to standardize (blistering, rusting, adhesion, porosity, gloss, color, hardness, flexibility) as well as SEM, EDXS, and electrochemical impedance spectra tests. Based on the good correlation between them, but mainly in the fact that they were demonstrative of the very slow deterioration rate of the polyurethane paint/pretreated electrogalvanised steel sheets/aerated $01 . \mathrm{M} \mathrm{Na}_{2} \mathrm{SO}_{4}$ or $0.05 \mathrm{M} \mathrm{NaCl}$ solution, it was possible to assume that adding a compatible primer to improve the pretreatment/paint adhesion, the resulting duplex system could become an acceptable protective alternative under similar exposure conditions.

\section{ACKNOWLEDGEMENTS}

The authors acknowledge CAPES/MINCyT (Process 158/09 of Brazil e BR/08/04 of Argentina), and Comisión de Investigaciones Científicas de la Provincia de Buenos Aires (CICPBA), Consejo Nacional de Investigaciones Científicas y Técnicas (CONICET) and Universidad Nacional de La Plata (UNLP) of Argentina for their financial support to this research.

\section{COMPETING INTERESTS}

Authors declare that there are no competing interests.

\section{REFERENCES}

1. Zhang XG. Corrosion and Electrochemistry of Zinc, Plenum Press, New York. $1006 ; 16-17$. 
2. ASM Handbook, Surface Engineering. 1999;5:405-406.

3. Cape T. Non-Hexavalent Chromium Coating Technologies for Galvanized Steel. Galvanizers Association Conference, Montreal, QC; 2007.

4. Directive 2002/95/Ec of the European Parliament and of the Council of 27 January 2003 on the restriction of the use of certain hazardous substances in electrical and electronic equipment. Official Journal of the European Union. 2003;L37:19-23.

5. Bellezze T, Roventi G, Fratesi R. Electrochemical Study on the Corrosion Resistance of Cr III-Based Conversion Layers on Zinc Coatings. Surf. Coat. Technol. 2002;155(23):221-230.

6. Ogle K, Morel S, Meddahi N. An electrochemical study of the delamination of polymer coatings on galvanized steel. Corros. Sci. 2005;47:2034-2052.

7. Deflorian F, Rossi S, Kamarchik P, Fedrizzi L, Bonora PL. Degradation mechanism of electrodeposited coatings in alkaline solutions. Prog. Org. Coat. 2003;47:103-111.

8. Zapponi M, Elsner Cl, Actis F, Di Sarli AR. Correlation between accelerated tests and outdoor exposure of coil-coated chromate and chromate free systems. Corros. Eng. Sci. Technol. 2009;44(3):119-127.

9. Blustein G, Di Sarli AR, Jaen JA, Romagnoli R, del Amo B. Study of iron benzoate: as a novel steel corrosion inhibitor pigment for protective paint films. Corros. Sci. 2007;49:4202-4231.

10. Deyá M, Di Sarli, AR del Amo B, Romagnoli R. Performance of anticorrosive coatings containing tripolyphosphate in aggressive environments. Indust. Eng. Chem. Res. 2008;70(18):7038-7047.

11. Rosales BM, Di Sarli AR, de Rincón O, Rincón A, Elsner Cl, Marchisio B, Flores S, Rivero $S$, An evaluation of coil coating formulations in aggressive environments. Prog. Org. Coat. 2004;50(2):105-114.

12. del Amo B, Véleva L, Elsner Cl, Di Sarli AR. Performance of coated steel systems exposed to different media. Part I: painted galvanized steel. Prog. Org. Coat. 2004;50(3):179-192.

13. Elsner $\mathrm{Cl}$, Cavalcanti E, Ferraz O, Di Sarli AR. Evaluation of the surface treatment effect on the anticorrosive performance of paint systems on steel. Prog. Org. Coat. 2003;48(1):50-62.

14. De Rosa L, Monetta T, Bellucci F, Mitton DB, Atienza A, Sinagra C. The effect of a conversion layer and organic coating on the electrochemical behavior of 8006 and 8079 aluminum alloys. Prog. Org. Coat. 2002;44:153-160.

15. Emira HS, Abdel-Mohsen FF. The dependence of the corrosion protection of waterborne paints on the concentration of the anticorrosive pigment. Pigment \& Resin Technol. 2003;32(4):259-265.

16. Bardage SL, Bjurman J. Adhesion of waterborne paints to wood. J. Coat. Technol. 1998;70(878):39-47.

17. González I, Mestach D, Leiza JR, Asua JM. Adhesion enhancement in waterborne acrylic latex binders synthesized with phosphate methacrylate monomers. Prog. Org. Coat. 2008;61:38-44.

18. Nabuurs T, Baijards RA, German AL. Alkyd-acrylic hybrid systems for use as binders in waterborne paints. Prog. Org. Coat. 1996;27:163-172.

19. Topçuoglu O, Altinkaya SA, Balköse D. Characterization of waterborne acrylic based paint films and measurement of their water vapor permeabilities. Prog. Org. Coat. 2006;56:269-278.

20. Almeida E, Santos D, Uruchurtu J. Corrosion performance of waterborne coatings for structural steel. Prog. Org. Coat. 1999;37:131-140. 
21. Ahmad S, Ashraf SM, Riaz U, Zafar S. Development of novel waterborne poly(1naphthylamine)/poly(vinylalcohol)-resorcinol formaldehyde-cured corrosion resistant composite coatings. Prog. Org. Coat. 2008;62:32-39.

22. Hernández M, Genescá J, Uruchurtu J, Galliano F, Landolt D. Effect of an inhibitive pigment zinc-aluminum-phosphate (ZAP) on the corrosion mechanisms of steel in waterborne coatings. Prog. Org. Coat. 2006;56:199-206.

23. Dhoke SK, Khanna AS. Effect of nano- $\mathrm{Fe}_{2} \mathrm{O}_{3}$ particles on the corrosion behavior of alkyd based waterborne coatings. Corros. Sci. 2009;51:6-20.

24. Galliano F, Landolt D. Evaluation of corrosion protection properties of additives for waterborne epoxy coatings on steel. Prog. Org. Coat. 2002;44:217-225.

25. Aznar AC, Pardini OR, Amalvy Jl. Glossy topcoat exterior paint formulations using water-based polyurethane/acrylic hybrid binders. Prog. Org. Coat. 2006;55:43-49.

26. Zubielewicz M, Gnot W. Mechanisms of non-toxic anticorrosive pigments in organic waterborne coatings. Prog. Org. Coat. 2004;49:358-371.

27. Fujitani T. Stability of pigment and resin dispersions in waterborne paint. Prog. Org. Coat. 1996;29:97-105.

28. Kreutz S. Mudanças e adaptações trazem menor toxicidade ambiental. Tintas \& Vernizes, Portuguese. 2000;189:24-28.

29. Thometzek P, Ludwig A, Karbach A, Köhler K. Effects of morphology and surface treatment of inorganic pigments on waterborne coating properties. Prog. Org. Coat. 1999;36:201-209.

30. Reuter E, Silber DS, Psiorz DC. The use of new block copolymeric dispersing agents for waterborne paints-theoretical and practical aspects. Prog. Org. Coat. 1999;37:161-167.

31. Le Pen C, Lacabanne C, Pebere N. Structure of waterborne coatings by electrochemical impedance spectroscopy and a thermo stimulated current method: influence of fillers. Prog. Org. Coat. 2000;39:167-175.

32. Guillaumin V, Landolt D. Effect of dispersion agent on the degradation of a water borne paint on steel studied by scanning acoustic microscopy and impedance. Corros. Sci. 2002;44(1):179-189.

33. Galliano F, Landolt D. Evaluation of corrosion protection properties of additives for waterborne epoxy coatings on steel. Prog. Org. Coat. 2002;44(3):217-225.

34. Athey RD. Polymer/natural-hydrocarbon emulsions. Eur. Coat. J. 1991;3:117-125.

35. Kossmann H. Simulation of ambient effects in testing anticorrosion paints, Proc. Annual Technical Meeting, Institute of Environmental Sciences, Anaheim, CA, USA. 1989;43-47.

36. Flynn RW. Development of Polymers for Water-Based Maintenance Finishes. Mat. Perform. 1995;32-35.

37. Chapman M. Water-based anticorrosive systems. Eur. Coat. J. 1991;9:540-552.

38. Hofland A. Making paint from alkyd emulsions. ACS Symposium Series. 1997;663:183-195.

39. Nysteen S. Practical experience with air-drying waterborne paints for the protection of structural steelwork and freight containers. Surf. Coat Technol. 1994;77(7):311-315.

40. Neffgen B. Environment-friendly, cold-curing epoxy systems. Eur. Coat. J. 1996;10:700-703.

41. Weinmann DJ, Dangayachand K, Smith C. Amine functional curatives for low temperature cure epoxy coatings. J. Coat. Technol. 1996;68:29.

42. Cornwell DW. Developments in water based and low VOC coatings for the protection of structural steel. Corros. Manage. 1994;2:13-15. 
43. Gardon JL. A perspective on resins for aqueous coatings. Prog. Org. Coat. 1997;32:73.

44. Athey RD. Additives for waterborne coatings. Eur. Coat. J. 1996;6:420-423.

45. Hester DH, Squire DR. Rheology of waterborne coatings. J. Coat. Technol. 1997;69(864):109-114.

46. Johnson R. An overview of waterborne coatings: A formulator's perspective. J. Coat. Technol. 1997;69(864):127-129.

47. Reinhard G. Formulation of water-borne dispersions for corrosion-protective primers. Prog. Org. Coat. 1990;18(2):123-145.

48. De Rosa L, Monetta T, Milton DB, Bellucci F. Monitoring Degradation of Single and Multilayer Organic Coatings. I. Absorption and Transport of Water: Theoretical Analysis and Methods. J. Electrochem. Soc. 1998;145(11):3830-3838.

49. Zwinselman J. Propylene glycol diethers in water-based coatings. Eur. Coat. J. 1990;10:514-524.

50. Morgan RE. Zero VOC coating technology - Innovative solutions for old problems. Mater. Perform. 1996;35:31-36.

51. Liu B, Li Y, Lin HC. Study on the anti-corrosion performance of acrylic-polyurethane. J. Chin. Soc. Corros. Prot. 2003;23:89-91.

52. Zhu Y, Xiong J, Tang Y, Zuo Y. EIS study on failure process of two polyurethane composite coatings. Prog. Org. Coat. 2010;69:7-11.

53. Chattopadhyay DK, Raju KVSN. Structural engineering of polyurethane coatings for high performance applications, Prog. Polym. Sci. 2007;32:352-418.

54. Fratricova M, Simon $P$, Schwarzer $P$, Wilde $P$. Residual Stability of Polyurethane Automotive Coatings Measured by Chemiluminescence and Equivalence of Xenotest and Solisi Ageing Tests, Polym. Degrad. Stabil. 2006;91:94-100.

55. Armstrong RD, Jenkins ATA, Johnson BW. An investigation into the UV breakdown of thermoset polyester coatings using impedance spectroscopy. Corros. Sci. 1995;37(10):1615-1625.

56. Zhang JT, Hu JM, Zhang JK. Studies of impedance models and water transport behaviors of polypropylene coated metals in $\mathrm{NaCl}$ solution. Prog. Org. Coat. 2004;49:293-301.

57. González-García Y, González S, Souto RM. Electrochemical and structural properties of a polyurethane coating on steel substrates for corrosion protection. Corros. Sci. 2007;49(9):3514-3526.

58. Marchebois Savall C, Bernard J, Touzain S. Electrochemical behavior of zinc-rich powder coatings in artificial sea water. Electrochem. Acta. 2004;49(17-18):2945-2954.

59. ASTM D1210-05, Standard Test Method for Fineness of Dispersion of PigmentVehicle Systems by Hegman-Tyoe Gage; 2010.

60. ISO 2808-2007, Paint and Varnishes-Determination of the Film Thickness; 2010.

61. ASTM D3359-09e2, Standard Test Methods for Measuring Adhesion by Tape Test.

62. ASTM D5162-08, Standard Practice for Discontinuity (Holiday) Testing of Nonconductive Protective Coating on Metallic Substrate.

63. ASTM D523-08, Standard Test Methods for Specular Gloss.

64. ASTM D2244-09b, Standard Practice for Calculation of Color Tolerances and Color Differences from Instrumentally Measured Color Coordinates.

65. ASTM D3363-05 e2, Standard Test Methods for Film Hardness by Pencil Test; 2011.

66. ASTM D 522-93a-08, Standard Test Methods for Mandrel Bend Test of Attached Organic Coatings. 
67. ASTM D-714-02, Standard Test for Evaluating Degree of Blistering of Paints, and ASTM D-610/08 Standard Practice for Evaluating Degree of Rusting on Painted Steel Surfaces, respectively; $2009 \& 2012$.

68. Boukamp BA. "Equivalent Circuit", report CT88/265/128, CT89/214/128, University of Twente, The Netherlands, 1989.

69. Deck PD, Reichgott DM. "Characterization of Chromium-Free No-Rinse Prepaint Coating on Aluminum and Galvanized Steel." Met. Finish. 1992;9(90):29-35.

70. Barbucci M, Delucchi M, Cerisola G. "Study of Chromate-Free Pretreatments and Primers for the Protection of Galvanized Steel Sheets." Prog. Org. Coat. 1998;33(2):131-138.

71. Wilcox GD, Wharton JA. "A Review of Chromate-Free Passivation Treatments for Zinc and Zinc Alloys." Trans. IMF, 1997;75(4):B140-B146.

72. Duarte RG, Bastos AC, Castela AS, Ferreira MGS. A Comparative Study Between $\mathrm{Cr}(\mathrm{VI})$-Containing and $\mathrm{Cr}$-Free Films for Coil Coating Systems. Prog. Org. Coat. 2005;52(4):320-327.

73. Montemor MF, Simões AM, Ferreira MGS, Breslin CB. Composition and Corrosion Behavior of Galvanized Steel Treated with Rare-Earth Salts: The Effect of the Cation. Prog. Org. Coat. 2002;44(2):111-120.

74. Trabelsi W, Cecilio P, Ferreira MGS, Montemor MF. Electrochemical Assessment of the Self-Healing Properties of Ce-Doped Silane Solutions for the Pre-treatment of Galvanized Steel Substrates. Prog. Org. Coat. 2005;54(4):276-284.

75. Johnson BY, Edington J, Williams A, O'Keefe MJ. Microstructural Characteristics of Cerium Oxide Conversion Coatings Obtained by Various Aqueous Deposition Methods. Mater. Charact. 2002;54(1):41-48.

76. Trabelsi W, Triki E, Dhouibi L, Ferreira MGS, Zheludkevich ML, Montemor MF. The Use of Pre-treatments Based on Doped Silane Solutions for Improved Corrosion Resistance of Galvanized Steel Substrates. Surf. Coat. Technol. 2006;200(1415):4240-4250.

77. Ferreira MGS, Duarte RG, Montemor MF, Simões AMP. Silanes and Rare Earth Salts as Chromate Replacers for Pre-treatments on Galvanized Steel. Electrochim. Acta. 2004;49(17-18):2927-2935.

78. Peultier J, Rocca E, Steinmetz J. Zinc Carboxylating: A New Conversion Treatment of Zinc. Corros. Sci. 2003;45(8):1703-1716.

79. Zhang X, van den Bos C, Sloof WG, Hovestad A, Terryn H, de Wit JHW. Comparison of the morphology and corrosion performance of $\mathrm{Cr}(\mathrm{VI})$ - and $\mathrm{Cr}(\mathrm{III})$-based conversion coatings on zinc. Surf Coat Technol. 2005;199(1):92-104.

80. Tomachuk CR, Elsner $\mathrm{Cl}$, di Sarli AR. Corrosion Resistance Of $\mathrm{Cr}$ (III) Conversion Treatments Applied On Electrogalvanised Steel And Subjected To Chloride Containing Media. Mat Chem Phys. 2009;119(1-2):19-29.

81. Tomachuk $\mathrm{CR}$, Elsner $\mathrm{Cl}$, di Sarli AR. Morphology And Corrosion Resistance Of Cr(III)-Based Conversion Treatments Applied On Electrogalvanised Steel. J Coat Technol Res. 2010;7(4):493-502.

82. Martyah NM, McCaskie JE, Harrison L. Corrosion behavior of zinc chromate coatings. Met. Finish. 1996;94(2):65-67.

83. Martyah NM. Internal stresses in zinc-chromate coatings. Surf. Coat. Technol. 1996;88(1-3):139-146.

84. Zhang X, Böhm S, Bosch AJ, van Westing EPM, de Wit JHW. Influence of drying temperature on the corrosion performance of chromate coatings on galvanized steel. Mat. Corros. 2004;55(7):501-510. 
85. Zsauer T, Brandt A. Impedance measurements on zinc-rich paints, J. Oil Col. Chem. Assoc. 1984;67(1):13-17.

86. Frydrych DJ, Farrington GC, Townsend H. Corrosion Protection by Organic Coatings (M.W. Kendig and H. Leidheiser, Jr., eds.), The Electrochemical Society, Pennington, NJ. 1987;87(2):240.

87. Rapports d'activite du laboratoire IVP Biennale 1975-1977, p. 20, Internal Report of IVP, Belgium. French

88. Szklarska-Smialowska Z. Passivity of Metals, R.P. Frankenthal and J. Kruger, eds., The Electrochemical Soc. Corrosion Monographs Series, Princeton, NJ. 1978;443.

89. Vetter KJ. Electrochem. Kinetics, Academic Press, NY, 1967;754.

90. Piens M. Importance of diffusion in the electrochemical action of oxidizing pigments. J. Coat. Technol. 1979;51(655):66-73.

91. Leidheiser H Jr Funke W. Water disbondment and wet adhesion of organic coatings on metal: A review and interpretation. J. Oil Col. Chem. Assoc. 1987;70(5):121-132.

92. Schwenk W. Corrosion Control by Organic Coatings, Leidheiser, H. Jr. ed., NACE, Houston, TX. 1981;103.

93. Hinton BRW. Corrosion prevention and chromates, the end of an era? Met. Finish. 1991;89:55-61.

94. Hinton BRW. Corrosion prevention and chromates: the end of an era? Met. Finish. 1991;89:15-20.

95. Hubrecht JC, Vereecken J. Study of the anodic and cathodic corrosion process of coated iron with the ac Impedance technique, Proc. $9^{\text {th }}$ Int. Cong. On Metallic Corrosion, Toronto. 1984;3:85-90.

96. Szauer T. Electrical and electrochemical resistances for the evaluation of protective nonmetallic coatings. Prog. Org. Coat. 1982;10(2):157-170.

97. Elsner $\mathrm{Cl}$, Di Sarli AR. Comparation Between Electrochemical Impedance And Salt Spray Tests In Evaluating The Effect Of Epoxy Paints. J. Braz. Chem. Soc. 1994;5:1518.

98. Dunham KJ. Preparing hot-dip galvanized steel surfaces for painting or powder coating: a primer. Met. Finish. 2002;100(9):20-25.

99. Zhang XG. In "Corrosion and Electrochemistry of Zinc," Plenum Press, NY.1996;6;157.

100. Townsend HE, Hart RG. Composition of Chromate Passivation Films on Al-Zn AlloyCoated Sheet Steel. J. Electrochem. Soc.: Solid-State Sci. Technol. 1984;131(6):1345-1348.

101. Pérez C, Collazo A, Izquierdo M, Merino P, Nóvoa XR. Electrochemical Impedance Spectroscopy Study of the Corrosion Process on Coated Galvanized Steel in a Salt Spray Fog Chamber. Corrosion. 2000;56(12):1220-1232.

102. Stratman $M$, Streckel $H$, Fezer R. A new technique able to measure directly the delamination of organic polymer films. Corros. Sci. 1991;32(4):467-470.

103. Bierwagen GP, He L, Li J, Ellingson L, Tallman, DE. Studies of a new accelerated evaluation method for coating corrosion resistance-thermal cycling testing. Prog. Org. Coat. 2000;39:67-78.

104. Leidheiser $\mathrm{H}$ Jr. Electrical and Electrochemical measurements as predictors of corrosion at the metal-organic coating interface. Prog. Org. Coat. 1979;7(1):79-104.

105. Szauer T. Impedance measurements for the evaluation of protective nonmetallic coatings. Prog. Org. Coat. 1982;10(2):171-183. 
106. Vilche JR, Bucharsky E, Giudice CA. Application of EIS and SEM to evaluate the pigment shape and content in ZRP formulations on the corrosion prevention of naval steel. Corros. Sci. 2002;46(6):1287-1309.

107. Hornus Sack S, Romagnoli R, Vetere VF, Elsner Cl, Pardini O, Amalvy JI, Di Sarli AR. Evaluation of Steel/Primer Based On Chestnut Tannin/Paint Film Systems by EIS. J. Coat. Technol. 2002:74(926):63-69.

108. Zhang $X G(E d$.$) , Corrosion and Electrochemistry of Zinc, Plenum Press, New York.$ $1996 ; 5$.

(c) 2014 Di Sarli et al.; This is an Open Access article distributed under the terms of the Creative Commons Attribution License (http://creativecommons.org/licenses/by/3.0), which permits unrestricted use, distribution, and reproduction in any medium, provided the original work is properly cited.

Peer-review history:

The peer review history for this paper can be accessed here:

http://www.sciencedomain.org/review-history.php?iid=366\&id=5\&aid=2703 